\title{
Artículo de investigación \\ Correlation between the clinical stage, echocardiographic findings and systemic blood pressure in dogs with Degenerative Disease of the Mitral Valve
}

Correlación entre el estadio clínico, los hallazgos ecocardiográficos y la presión arterial sistémica en caninos con Enfermedad Degenerativa de la Válvula Mitral

Correlação entre os clínicos, ecocardiográficos e pressão arterial sistêmica em cães com doença degenerativa da Válvula Mitral

Víctor Leonel Ramírez ${ }^{1 \text { Mv, MS: CvLAC }}$, Alina Berrío ${ }^{2 \text { Mvz, MS; CvLAC }}$, María Patricia Arias ${ }^{2}$ Mv, MS, PhD; CvLAC

Correspondence date:

Received: 16 de febrero de 2016. Accepted: 5 de agosto de2016.

To cite this article:

Ramírez VL, Berrío A, Arias MP. Correlation between the clinical stage, echocardiographic findings and systemic blood pressure in dogs with Degenerative Disease of the Mitral Valve. Rev. CES Med. Zootec. 2016; Vol 11 (2): 61-72.

Open access

(C) Copyright

Creative commons

Éthics of publications

Peer review

Open Journal System

e-ISSN 1900-9607

DOl: http://dx.doi.org/10.21615/ cesmvz.11.2.5

Share

\begin{abstract}
Background: most studies about Degenerative Mitral Valve Disease (DMVD) in dogs have focused on studying the echocardiographic (ECG) changes without considering changes in systolic, diastolic or mean blood pressure. Objective: to relate echocardiographic alterations and systemic pressure with the clinical stage in patients with DMVD. Methods: a random sample of 23 dogs with DMVD was obtained. A clinical classification of patients was performed based on criteria of the ACVIM. Blood pressure was taken with high-definition oscillometry equipment (HDO-2112-Vet) and then, patients underwent echocardiographic examination. Ultrasonographic features of the valve apparatus were assessed qualitatively, specifically the presence of thickening and prolapse of leaflets and remodelative changes, heart rate (HR), left atrium and aorta ratio (LA/AO), fractional shortening (FS), trans-valvular flows and pressure gradients were calculated as well. The confidence level was set at $95 \%$. An univariate analysis was employed, as well as an ANOVA followed by a Fisher's test; Pearson's correlation was applied. Results: in the echocardiographic evaluation, statistically significant differences were observed between stages B1, B2 and C for the variables LA/AO, FS, and mitral gradient. There was a direct correlation between FS and mitral gradient $(r=0.66), L A / A O$ and mitral gradient $(r=0.70)$, and $\mathrm{LA} / \mathrm{AO}$ and FS, $(r=0.75)$. An inverse correlation was found between systolic arterial pressure and FS $(r=0.51)$. Conclusions: patients with EDVM on stage $C$ tended to have lower values tension; therefore, clinical evaluation with repeated blood pressure measurements in the same patient can help in decision-making and classification of the disease process. Among echocardiographic variables, the FS and LA/AO ratio were directly related to the clinical stage of the DMVD.
\end{abstract}

Keywords: cardiomyopathy, echocardiography, high definition oscillometry, remodelative changes, arterial pressure. 


About authors:
${ }^{1}$ Centro de Medicina Veterinaria
y Zootecnia, Universidad
CES. AA 054591, Medellín,
Colombia; Facultad de Medicina
Veterinaria y Zootecnia,
Universidad CES. AA 054591,
Medellín, Colombia.
${ }^{2}$ Linea de Investigación
en Fisiopatología, Facultad
de Medicina Veterinaria,
Universidad CES, Calle 10 No
43 A 50, oficina 235, Barrio el
Poblado, Medellín, Colombia.

\section{Resumen}

Antecedentes: la mayoría de estudios sobre la Enfermedad Degenerativa de la Válvula Mitral (EDVM) en caninos se han enfocado en estudiar los cambios ecocardiográficos (ECG) sin considerar los cambios en la presión arterial sistólica, diastólica o media. Objetivo: relacionar las alteraciones ecocardiográficas y de presión sistémica con el estadio clínico en pacientes con EDVM. Métodos: se obtuvo una muestra al azar de 23 caninos con EDVM. Se realizó la clasificación del paciente según los criterios de la ACVIM. Se tomó la presión arterial con un equipo de oscilometría de alta definición (Vet-HDO-2112). Las características ultrasonográficas del aparato valvular fueron evaluadas cualitativamente, específicamente la presencia de engrosamiento y prolapso de valvas y los cambios remodelativos, la frecuencia cardíaca (FC), la relación Al/AO, la fracción de acortamiento, los flujos trans-valvulares y se calcularon los gradientes de presión. El nivel de confianza establecido fue del 95\%. Se realizó un análisis univariado, prueba de ANOVA y el test de Fisher y se aplicó la correlación de Pearson. Resultados: en la evaluación ecocardiográfica se observó diferencia estadística significativa entre los estadios B1, B2 y C para las variables Al/A0, FA y gradiente mitral, una correlación directa entre FA y gradiente mitral $(r=0,66), A l / A 0$ y gradiente mitral $(r=0,70)$, y entre Al/AO con FA $(r=0,75)$, y una correlación inversa entre la presión arterial sistólica y FA $(r=0,51)$. Conclusión: los pacientes con EDVM en estadio $\mathrm{C}$ mostraron tendencia a presentar valores más bajos de presión arterial, por ende, la evaluación clínica con mediciones repetidas de la presión arterial en el mismo paciente puede ayudar en la toma de decisiones y en la clasificación del proceso mórbido. Entre las variables ecocardiográficas, la FA y la relación Al/AO se relacionaron de manera directa con el estadio clínico de EDVM.

Palabras clave: cambios remodelativos, cardiomiopatía, ecografía, oscilometría de alta definición, presión arterial.

\section{Resumo}

Antecedentes: a maioria dos estudos sobre a Doença Degenerativa da Valva Mitral (EDVM) em cães têm sido foco em estudar alterações no ECG, independentemente de alterações na pressão arterial sistólica, pressão arterial diastólica ou média. Objetivo: relacionar ecocardiográfica e pressão sistêmica e estágio clínico em pacientes com EDVM. Métodos: foi obtida uma amostra aleatória de 23 cães com EDVM. Houve um exame clínico seguido de classificação clínica de um paciente com base nos critérios do American College of Veterinary Internal Medicine (ACVIM). A pressão arterial foi tirada com uma Oscillometry alta definição automática (HDO-2112-Vet). Os pacientes foram submetidos a exame ecocardiográfico. Ele foi avaliado qualitativamente características ultra-sonográficos do aparelho valvar, específicamente a Presença de espessamento e / ou prolapso de folhetos e mudanças remodelative, $H R$, relação $A E / A O$, fração de encurtamento $(F E)$, os fluxos trans-valvar e pressão, em seguida, calculou-se gradientes. 0 nível de confiança foi de 95\% em setembro. Foi realizada análise de variância, seguida pelo teste de Fisher, correlação de Pearson foi aplicado. Resultados: a avaliação ecocardiográfica, foi observada diferença estatisticamente significativa entre as fases B1, B2 e C para as variáveis Al/AO, FE e gradiente mitral. Houve uma correlação direta entre a \% de Gordura e gradiente mitral $(r=0,66), A l / A O$ e gradiente mitral $(r=0,70)$, e entre Al / AO com de gordura $(r=0,75)$ e uma correlação inversa entre a Pressão Arterial Sistólica e FE ( $r=$ 0,51). Conclusões: pacientes com EDVM fase em $\mathrm{C}$ eles tendem a ter valores tensão, portanto, avaliação clínica com medições de pressão arterial repetidas no mesmo 
paciente pode ajudar na tomada de decisões e classificação do processo da doença. Entre as variáveis ecocardiográficas, FE e relação Al/AO estavam directamente relacionados com o estágio clínico da EDVM.

Palavras-chave: cardiomiopatia, mudanças remodelativos, oscilometria, pressão arterial, ultrasom de alta definição.

\section{Introduction}

Degenerative Mitral Valve Disease (DMVD) is the most prevalent cardiac disease found in canines (Atkins et al., 2009; Serres et al., 2008; Côté 2005; Gómez, 2004). DMVD is accompanied by changes in the heart function and structure, with hemodynamic aftermaths and alterations in the systemic arterial pressure that finally exceed the ability of compensatory mechanisms in the body, leading to various degrees of congestive heart failure (Gómez, 2004; Nyland y Mattoon, 2004; Tou et al., 2006).

Mitral regurgitation produces cardiovascular alterations related with changes of systolic volume and blood pressure (Tou et al., 2006). On one hand, the echocardiographic findings show an increase in leaflet thickness, atrial and left ventricular dilatation, eccentric hypertrophy of the left ventricle and an increase of the left ventricular systolic function, findings related to the severity of the clinical signs (Nyland y Mattoon, 2004). On the other hand, cardiac output decreases, which theoretically triggers a reduction in blood pressure ( $\underline{\mathrm{Hall}, 2008)}$ ). In canines, primary hypertension is defined as a sustained increase in blood pressure without being associated with an identifiable cause, while secondary hypertension is associated with multisystem diseases, such as chronic kidney disease, Cushing's desease, diabetes mellitus, hyperaldosteronism, pheochromocytoma and hypothyroidism (Brown, 2007).

Currently, there are two non-invasive methods for measuring blood pressure in dogs: the doppler ultrasonography and oscillometry (Brown, 2007). The accuracy of these methods has been evaluated in canines with normal pressure (Bodey, 1996; Stepien RL, 1999; Chalifoux A, 1985), hypertensive, (Chalifoux A, 1985), both conscious (Bodey, 1996; Stepien RL, 1999) and anesthetized (Chalifoux A, 1985). Oscillometry in particular, is a noninvasive method of easy application that allows to measure with accuracy the systolic pressure (SBP), diastolic pressure (DBP), mean pressure (MAP) and heart rate (HR) in canines (Chetboul, 2010), and its proper use requires little training from clinicians. Due to the fact that oscillometry equipment for measuring blood pressure in dogs is relatively new in the market, until recently, its measurement by this method was rarely part of cardiological examination in patients with cardiac issues. However, the use of such equipment is becoming increasingly common.

Most studies about DMVD in canines have focused on studying echocardiographic (ECG) changes, without regard to changes in blood pressure, and it is still not clear whether patients with DMVD show alterations in systolic, diastolic or mean blood pressure. The goal of the present study was to relate the echocardiographic and systemic pressure alterations with the clinical stage of patients with DMVD.

\section{Materials and methods}

An observational, analytical, cross-sectional study of correlation was conducted. The Ethics Committee for Animal Experimentation of the University of Antioquia granted the approval to carry out this research (act $N^{\circ} 73,2011$ ). 
Twenty-three dogs from Medellín (Antioquia, Colombia, South América), regardless of breed or gender that had been diagnosed with DMVD without previous pharmacological treatment were selected randomly to be studied. All dogs were older than 3 years. Patients with different cardiac issues, such as: infective endocarditis, valve disease or congenital malformation, dilated cardiomyopathy and pulmonary valve or aortic disease, or that showed a pulmonary disease of non-cardiogenic origin, like tumors, metastasis, thrombo-embolism and other respiratory system or pulmonary parenchymal disorders that can cause pulmonary hypertension from different origin of the mitral insufficiency were excluded.

\section{Anamnesis}

Owners were interviewed to figure out the clinical behavior of patients, the reason for consultation, and the presentation of clinical signs such as cough, exercise intolerance, and episodes of syncope.

\section{Clinical examination}

A general clinical examination was conducted. Variables such as weight, body condition, heart rate, respiratory rate, capillary refill time and temperature were recorded. After patient cardiac assessment, a clinical classification was performed based on the criteria of The American College of Veterinary Internal Medicine (ACVIM) in 5 groups: A, B1, B2, C and D (Atkin et al., 2009). Canines with classification A and D were both excluded. Animals with classification A do not show symptomatology of heart failure and the study only considers breeds predisposed to develop cardiac issues, while dogs with classification $B$ had received previous medical treatment, this being an exclusion criterion established for this study. Finally, the presentation of other clinical variables was evaluated, namely: everyday behavior, orthopneic position, the presence of heart murmur, cough, cyanosis, hypoperfusion, dyspnoea, tachypnea, tachycardia, ascites, and arrhythmia.

\section{Blood pressure measurement}

Blood pressure measurements were taken from the evaluated patients followed by a clinical examination with a high-definition automatic oscillometry equipment (VetHD0-2112, Germany). This equipment detects pressure fluctuations throughout a cuff; this being a method that yields reliable results for taking blood pressure in dogs (Henik et al., 2005).

For this study, the cuff size was selected according to the size of each patient. With the patient sitting down, the cuff was placed on the upper left limb, distal to the elbow at the height of the median artery; then, the equipment was switched on to automatically inflate the cuff to a suprasystemic pressure of $200 \mathrm{mmHg}$, and then allowed to deflate slowly to a pressure of $25 \mathrm{mmHg}$. The equipment automatically determined the mean arterial blood pressure (MBP), systolic blood pressure (SBP), diastolic blood pressure (DBP) and pulse (Binns et al., 1995). Blood pressure measurements were taken by the same person, in a quiet environment away from other animals. Blood measurements were taken 10 times per patient over a 10-15 minute period, in order to minimize the bias due to lack of custom of patients to this process. Then, the mean of the values recorded was calculated. 
Patients who met the inclusion criteria underwent an echocardiographic examination which was performed on the patient in the lateral decubitus position using the equipment Esaote MyLab30 equipped with a cardiology module with B-mode, M-mode, Doppler color, spectral Doppler in pulsed wave (PW) and continuous wave (CW) modes. Sectorial transducers, phase array multi-frequency were used. None of the patients were sedated to avoid the influence of these drugs on the parameters to be studied.

Both long and short parasternal and apical basic planes in the cardiac axis were used, according to the technical indications described by Nyland (Nyland y Mattoon. 2004; Talavera, 2001). Initially, ecocardiographic features of the valve apparatus on B-mode were assessed qualitatively, specifically the presence of thickening and/or prolapse of leaflets, and remodelative changes that accompany this disease. Then, the following variables were taken on M-mode: heart rate (HR \# 2), left atrium and aorta ratio (LA/AO), fractional shortening $(F S)$ and finally transvalvular flows were evaluated with Doppler. The mitral thickening on B-mode was evaluated according to the presence of nodular structures, irregularity of the shape of the leaflet, the increase in size of the tip of the valve leaflet and the changes (decrease) in the echogenicity of the valve leaflets, according to Talavera, (2001). In the apical cut of the 4-chambers, after having identified with color Doppler the mitral regurgitation jet in the left atrium (LA), the maximum peak of the speed was measured with the CW and the pressure gradients were calculated (Nyland y Mattoon, 2004). Patients showing tricuspid regurgitation were intervened the same way.

Data analysis

All data was entered into an Excel spreadsheet ${ }^{\circledR}$. Data was analyzed using the statistical program Statgraphics. The confidence level was set at 95\%. A univariate analysis was employed, as well as an ANOVA followed by a Fisher's test; Pearson's correlation was also applied.

\section{Results}

Data analysis showed that the animals in the study had an average of $10.65 \pm 3.11$ years and an average body weight of $5.83 \pm 3.38 \mathrm{~kg}$. Of the patients $57 \%$ were females and $43 \%$ males. The French Poodle was the predominant breed (65\%), followed by Schnauzer (9\%), Yorkshire Terrier, Shih-Tzu, Pincher, Beagle, Crossbreed and Fox Terrier, each of these with a $4 \%$ stake in the study group.

\section{Clinical examination}

For the clinical assessment the clinical status, breed, and gender were taken as reference variables, and these were compared with the variables of heart rate, respiratory rate, temperature, tachycardia, arrhythmia, permanent cough, sporadic cough and cyanosis. The data obtained allowed to establish that there is a significant statistical difference between clinical stages B1 - C and B2 - C, and the variables permanent cough $(p=0.0006)$, sporadic cough $(p=0.0050)$, and cyanosis $(p=0.0026)$. For the variable dyspnea the difference was between the groups B2 $-C(p=0.0000)$. With respect to the capillary refill time, it was found that there is a statistical difference between the three groups $(p=0.0000)$. The remaining variables showed no statistical difference. When comparing the variables breed and sporadic cough, it was 
found that the patients in group B1 were equal to the ones in group B2 statistically speaking, unlike group $C(p=0.0176)$. The remaining variables showed no statistical difference. Regarding gender, there was no statistical difference between the clinic or echocardigraphic variables studied.

\section{Blood pressure}

Employing an ANOVA, statistically significant difference was detected for SBP, MBP, DBP and pulse variables, regarding the patient's condition. Blood pressure results are shown in table 1.

Table 1. Average values, standard deviation and $p$ value for the variables SBP, MBP, DBP and pulse, with respect to the patient's condition.

\begin{tabular}{ccccc}
\hline $\boldsymbol{P}(\boldsymbol{m m} \boldsymbol{H g})$ & $\boldsymbol{B 1}$ & $\boldsymbol{B 2}$ & $\boldsymbol{C}$ & $\boldsymbol{p ~ v a l u e *}^{*}$ \\
\hline SBP & $154.42 \pm 15.35^{\mathrm{a}}$ & $146.08 \pm 13.77$ & $124.67 \pm 20.03^{\mathrm{b}}$ & 0.0132 \\
MBP & $107.57 \pm 9.95$ & $103.15 \pm 14.09$ & $94.67 \pm 9.07$ & \\
DBP & $92.14 \pm 18.10^{\mathrm{a}}$ & $80.69 \pm 17.50^{\mathrm{b}}$ & $74.33 \pm 8.50$ & 0.0269 \\
PULSE & $114.86 \pm 24.55$ & $122.15 \pm 37.95$ & $183.00 \pm 72.92$ & \\
\hline
\end{tabular}

$\mathrm{SBP}=$ systolic blood pressure; MBP = mean arterial blood pressure, DBP = diastolic blood pressure Values of 0.05 indicate a statis tical difference with a confidence level of $95 \%$.

a, b Different superscript letters in the same row indicate a statistical difference between groups.

Data without superscript letters indicate no statistical difference with regards to the other groups of the same row

\section{Echocardiographic assessment}

As for the data obtained in the echocardiographic evaluation, ANOVA did not show a statistically significant difference between the clinic or ecocardiographic variables and the variables mitral thickening, mitral prolapse, and mitral jet. Variables that showed a statistical difference with respect to the clinical condition variable are shown in table 2.

Table 2. Average values, standard deviation, and $p$ value for echocardiographic variables with respect to the patient's condition.

\begin{tabular}{ccccc}
\hline Variable & B1 & B2 & $\boldsymbol{C}$ & $\boldsymbol{p ~ v a l u e}^{* * *}$ \\
\hline LA/AO ratio & $1.18 \pm 0.15^{\mathrm{a}}$ & $1.58 \pm 0.12^{\mathrm{b}}$ & $1.98 \pm 0.17^{\mathrm{c}}$ & 0.0001 \\
FA $^{*}$ & $43.14 \pm 1.35^{\mathrm{a}}$ & $53.62 \pm 4.39^{\mathrm{b}}$ & $60.67 \pm 4.16^{\mathrm{c}}$ & 0.0004 \\
MG $^{* *}$ & $14.40 \pm 13.99^{\mathrm{a}}$ & $69.91 \pm 21.23$ & $89.27 \pm 44.46^{\mathrm{b}}$ & 0.0171 \\
\hline
\end{tabular}

$\mathrm{LA} / \mathrm{AO}$ ratio= left atrium and aorta ratio; $F A=$ Fractional shortening; $M G=$ Mitral gradient.

* Values for the FS variable are shown as a percentage (\%).

** Values for the mitral gradient variable are expressed in $\mathrm{cm} / \mathrm{sec}$.

*** Values $<0.05$ indicate a statistical difference with a confidence level of $95 \%$.

a.b.c Different superscript letters in the same row indicate a statistical difference between groups.

Data without superscript letters indicate no statistical difference with respect to the other groups of the same row.

In regards to the patient's condition and the dilation of the atrial and ventricular left chambers, the study showed that there is a statistical difference between the groups B1 - B2 ( $p=0.0000$ y $p=0.0401$, respectively).

Measurements in the right chambers and heart valves were also conducted during the echocardiographic examination. The data analysis showed no statistically significant difference between the data obtained and the clinic variables. The same results were obtained for the maximum speeds in the aortic and pulmonary semilunar valves. 
When applying the Pearson correlation, a significant direct correlation was observed between the following variables: FS and mitral gradient $(r=0.66)$, between LA/ AO with mitral gradient $(r=0.70)$, and between LA/AO with FS $(r=0.75)$. Additionally, there was an inverse correlation between SBP and FS $(r=0.51)$.

\section{Discussion}

During clinical examination of canines, blood pressure values obtained by indirect measurement methods and under standard protocols are important tools for assessing the risk of harm in organs produced either by hypotension or hypertension, since an adequate pressure allows the correct perfusion throughout the whole body (Rondeau et al., 2013). The values obtained should be interpreted according to the condition and attitude of the patient, since factors such as anxiety, dehydration, among others, can alter transiently and negatively the real conditions of systemic blood pressure of the patient (Brown et al. 1998). Based on these statements, in this research the blood pressure measurement was performed according to Egner et al. (2007), who established reference values of systemic blood pressure in canines and felines through high-definition oscillometry (Egner et al., 2007; Brown et al., 2007), who defined some guidelines for management of hypertensive patients.

In the present study, it was found that patients with DMVD in the clinical stage $C$ had lower SBP values than patients in stages B1 and B2, however, the values of SBP, MBP, DBP were found between reference values described for small breeds in the canine species (Egner, 2007; Stepien, 1999; Chalifoux, 1985). This is consistent with the results obtained by Petit et al., (2013) as with the results described by Bogarelli et al., (2012), who found that dogs with DMVD in advanced stages of the disease (class $3 \mathrm{a}$ and $3 \mathrm{~b}$ ) showed mean arterial pressure values lower than the patients with stage 1 and 2 of the disease, according to the International Small Animal Cardiac Health Council System (ISACH) classification. Although Petit et al. (2013) conducted a prospective study in 103 patients with DMVD finding lower pressure values in stages $3 a$ and $3 \mathrm{~b}$ than in patients with stages 1 and 2 of DMVD, the results can be equated with the ones in the present study, because in both patients in clinical stages $3 \mathrm{a}$ and $3 \mathrm{~b}$ of the ISACH as well as the ones in stage $\mathrm{C}$ according to ACVIM, there is valvular damage with structural changes to the valve and previous signs of heart failure. According to the results of the present study it can be stated that with the progression of the disease there is a tendency to diminish blood pressure values, being that patients with greater severity of DMVD are those showing lower values of SBP, MBP, and DBP.

Although, similar to what Petit et al. (2013) in their prospective study found that dogs in advanced stage exhibit lower pressure values, one limitation of the current study was that DBP was not measured, which provides important information about the elasticity of blood vessels and the degree of affectation of themselves. In the present study it was found that DBP values in patients with DMVD in stage $C$ showed a tendency to be lower when compared with patients in clinical stages B1 and B2, although there was no significant difference between the different stages of the disease.

In this study, none of the patients was receiving any medical treatment for the disease, in fact, patients classified in clinical stages B1 and B2 were selected to meet the inclusion criteria. In the prospective study by Petit et al. (2013), patients treated with a variety of drugs were included, such as: furosemide, IECAs, pimobendan, spironolactone and nitroglycerin patches, therefore, researchers could not conclude whether low MBP values were associated with a decreased cardiac output, of the 
afterload, or both, due to the treatment used in these patients. The results described in the current study led to the conclusion that patients with DMVD in stage $\mathrm{C}$ without any medication had a lower MBP values.

In humans, the decrease of blood pressure in patients with DMVD is an indicator of negative prognostic (Spiegelstein et al., 2013). Although, dogs in the current study with DMVD in stage $C$ had lower blood pressure values with respect to patients with DMVD in stages B1 and B2, it is not possible to conclude whether this finding, as in humans, is of bad prognosis in the cardiac patient.

In patients with advanced heart failure, the heart is unable to keep the systolic volume necessary to achieve a perfusion pressure that allows the proper tissue oxygenation. In the early stages of the disease some compensatory mechanisms are turned on, such as the catecholamine secretion, the Frank-Starling mechanism and the myocardial hypertrophy to normalize cardiac output in a failing heart, however, in advanced stages of the disease, the aforementioned offsets are not enough to keep an adequate cardiac output (Spiegelstein et al., 2013). According to David et al. $\underline{(2013)}$ the contractile dysfunction in patients with remodeling is due to the alteration of the ventricular relaxation or the distensibility of the ventricular walls, with the subsequent appearance of systemic hypotension (David et al., 2013). Although, in the current study hypotension was not found in none of the patients, a tendency toward reduction was observed in the values of SBP, MBP, DBP, therefore, it would be important to conduct some studies in which blood pressure could be measured in patients in stage $\mathrm{D}$ of the disease to determine whether in canines, as in humans, hypotension occurs in the most advanced stage of the disease.

Canines with DMVD that develop congestive heart failure show signs like syncope and cough, caused by a marked left atrial dilatation that generates compression of the main left bronchus (Walasinee et al., 2009); due to these pathological changes, the medical management of the disease, often, does not help to stop the development and the progression of morphological alterations (Fox, 2012). Some patients with DMVD in stage $\mathrm{C}$ of the present study showed congestive signs such as cough, dyspnea and besides, exercise intolerance, suggesting that these patients had advanced physiopathologic changes as a result of the degeneracy of the valve apparatus and the mechanical dysfunction and mitral incompetence.

It has been described that in the DMVD is possible to observe irregular thickening of the free edges of the leaflets, which generally has a lower echogenicity than the normal valves, and presents an imperfect valve closure or incomplete coaptation, besides of the valvular flutter in diastole and valve prolapse inside of the left atrium in systole. (Nyland and Mattoon, 2004; Terzo, 2009 y Suzuki, 2013). In the canines of this study, the modifications described by other researchers were observed, although without any significant relation to the clinical stage, which can be explained by the variability in the presentation of clinical signs and the evolution of the disease in each patient. According to Gómez (2011), the signs evidenced in patients with congestive heart failure may be of very varied clinical presentation and little precise with respect to the disease.

Mitral regurgitation is the most common manifestation of DMVD in advanced stages, but these patients also show frequently ventricular remodeling and rupture of the tendineae chordae (Fox, 2011; Chetboul y Tissier, 2012). It has to be said that, in none of the patients, chordae tendineae rupture was observed despite having shown con- 
gestive signs. This can be explained because patients in stage $D$ were not included in the study, who in fact, are patients that show all the signs of patients in stage $\mathrm{C}$, but besides they have been refractory to the treatment according to the classification of the ACVIM, and their inclusion would have been a bias by preventing to determine if the systemic changes in pressure in these patients were due to the physiopathologic evolution or to the medication.

Atrial and left ventricular dilation of patients with DMVD is proportional to the degree of regurgitation and the valvular deterioration (Mark et al., 2003), and in turn, the valvular deterioration is associated with the deterioration of the cardiocirculatory function (Hezzell et al. 2012; Bonagura, 2009; Zacà 2007).

Likewise these authors, it was found that patients of this study had atrial and left ventricular dilatation associated with volume overload, and that this morphological alteration presented statistically significant difference among patients with clinical stage B1 and B2. With the help of M-mode echocardiography, other quantitative data were obtained as the FS and the LA/AO ratio that explain in a more direct manner the relationship between the degree of valvular regurgitation and the clinical stage of the disease. In the clinical practice, the LA/AO ratio is very useful to estimate the dilatation degree of the LA and the severity of the disease (Nyland and Mattoon, 2004; Bonagura, 2009). On the other hand, the FS is an index of ventricular function that increases as does the degree of clinical engagement of the patient with DMVD (Hezzell et al., 2012, Nyland and Mattoon, 2004; Bonagura, 2009); both the LA/AO ratio as well as the FS and their relation to clinical stages B1, B2 and C in this study behaved in a similar way.

Nowadays, it is unquestionable the importance of echocardiography for diagnosis of patients with DMVD, since this tool allows to reveal the morphological changes and functional status of the heart in patients with DMVD (Mark, 2003; Nyland and Mattoon, 2004; Terzo, 2009 y Suzuki 2013; Schober et al., 2010; Bernay et al., 2010; Chetboul y Tissier, 2012). Echocardiographic alterations have been widely studied in patients with DMVD, this, coupled with the increasingly easy access to echocardiography makes of this the main diagnostic tool for clinical assessment, tracking the disease evolution and thus determine the clinical classification of the patient. The measurement of the systemic blood pressure necessary in patients with DMVD is a complementary tool that coupled with echocardiographic changes can be used to establish the degree of systemic involvement. It has the advantage of being an economic process, of easy implementation and interpretation that, as well as the echocardiography procedure is a noninvasive method.

It is propose to continue the study with a larger sample size, including patients in stage $\mathrm{D}$ of the disease to determine the behavior of the blood pressure in these patients, besides conducting a clinical follow-up of the patients involved in the study. The B-mode, M-mode and Doppler echocardiography must be performed in patients with suspected DMVD to show the clinical stage, morphological changes, disease progression, patient prognosis and the management guidelines. According to the results of the current study, it is propose to measure the systemic blood pressure of patients with DMVD in order to complement the cardiological examination, especially in patients in advanced stages, due to the fact that it tends to decrease in patients in stage $\mathrm{C}$ of the disease; although preserving it within the reference ranges established for small breeds in canines species. 


\section{References}

Atkins C, Bonagura J, Ettinger S, Fox P, Gordon S, Haggstrom J, Hamlin R, Keene B, Fuentes $\mathrm{V}$ and Stepien R. Guidelines for the diagnosis and treatment of canine chronic valvular heart disease. J Vet Intern Med 2009; 23:1142-1150. http://www.ncbi. nlm.nih.gov/pubmed/19780929

Bernay F, Bland JM, Häggström J, Baduel L, Combes B, Lopez A, Kaltsatos V. Efficacy of spironolactone on survival in dogs with naturally occurring mitral regurgitation caused by myxomatous mitral valve disease. J Vet Intern Med 2010; 24:331-41. http://www.ncbi.nlm.nih.gov/pubmed/20102506

Binns S, Sisson D, Buoscio D, Schaeffer D. Doppler ultrosonographic, oscillometric and photoplesthymographic techniques for non invasive pressure measurements in anesthezies cats. J Vet Intern Med 1995; 9: 405-414. http://www.ncbi.nlm.nih.gov/ pubmed/8558488

Bodey AR, Michell AR, Bovee KC, Buranakurl C and Garg T. Comparison of direct and indirect (oscillometric) measurement of arterial blood pressure in conscious dogs. Res Vet Sci 1996; 61:17-21. http://www.ncbi.nlm.nih.gov/pubmed/8819188

Bonagura J.D, Schober K. E. Can ventricular function be assessed by echocardiography in chronic canine mitral valve disease?. J Small Anim Pract 2009; 50:12-249. http://www.ncbi.nlm.nih.gov/pubmed/19765216

Borgarelli M, Buchanan JW. Historical review, epidemiology and natural history of degenerative mitral valve disease. J Vet Cardiol 2012; 14: 93-101. http://www.ncbi. nlm.nih.gov/pubmed/22386588

Brown S, Atkins C, Bagley R, Carr A, Cowgill L, Davidson M, Egner B, Elliott J, Henik R, Labato M, Littman M, Polzin D, Ross L, Snyder P and Stepien R. Guidelines for the identification, evaluation, and management of systemic hypertension in dogs and cats. J Vet Intern Med 2007; 21:542-558. http://www.ncbi.nlm.nih.gov/pubmed/17552466

Brown SA, Henik RA: Diagnosis and treatment of systemic hypertension. Vet Clin North Am Small Anim Pract 1998; 28:1481-94. http://www.sciencedirect.com/ science/article/pii/S0195561698501337

Côté E. Echocardiography: common pitfalls and practical solutions. Clin Tech Small Anim Pract. 2005; 20:156-163. http://www.sciencedirect.com/science/article/pii/ $\underline{\mathrm{S} 1096286705000344}$

Chalifoux A, Dallaire A, Blais D, Lariviére N and Pelletier N. Evaluation of the arterial blood pressure of dogs by two noninvasive methods. Can J Comp Med 1985; 49:419423. http://www.ncbi.nlm.nih.gov/pmc/articles/PMC1236204

Chetboul V, Tissier R. Echocardiographic assessment of canine degenerative mitral valve disease. J Vet Cardiol 2012; 14: 127-148. http://www.sciencedirect.com/science/article/pii/S1760273412000173 
Chetboul V, Tissier R, Gouni V, De Almeida V, Lefebvre HP, Concordet D, Jamet N, Sampedrano C, Serres F, Pouchelon JL. Comparison of Doppler ultrasonography and high-definition oscillometry for blood pressure measurements in healthy awake dogs. AJVR. 2010; 71:776-772. http://www.ncbi.nlm.nih.gov/pubmed/20594078

David TE, Armstrong S, McCrindle BW, Manlhiot C. Determinants of left atrial reverse remodeling after valve surgery for degenerative mitral regurgitation. Circulation 2013; 22:2-10. http://www.ncbi.nlm.nih.gov/pubmed/23610981

Egner B, Carr A and Brown S. Essential Facts of Blood Pressure in Dogs and Cats, A Reference Guide. VBS VetVerlag, Babenhausen, Germany. 2007. http://www.worldcat.org/title/essential-facts-of-blood-pressure-in-dogs-and-cats-a-referenceguide/oclc/165333755/editions?referer=di\&editionsView=true

Fox P. Pathology of myxomatous mitral valve disease in the dog. J Vet Cardiol 2012; 14:103-126. http://www.ncbi.nlm.nih.gov/pubmed/22386587

Gómez L. Degeneración Valvular Mixomatosa. Análisis estadístico año 2003. Visión Veterinaria Mascota 2004; 19:20-24.

Gómez L. Degenerative valve disease in dogs: update on diagnosis, treatment and prognosis. Rev Colomb Cienc Pecu 2011; 24:201-208. http://www.scielo.org.co/scielo.php?script=sci arttext\&pid=S0120-06902011000200011

Hall DJ, Cornell CC, Crawford S, Brown DJ. Meta-analysis of normal canine echocardiographic dimensional data using ratio indices. J Vet Cardiol 2008; 10:11-23. http:// www.ncbi.nlm.nih.gov/pubmed/18486580

Hezzell MJ, Boswood A, Moonarmart W, Elliott J. Selected echocardiographic variables change more rapidly in dogs that die from myxomatous mitral valve disease. J Vet Cardiol 2012; 14:269-279. http://www.ncbi.nlm.nih.gov/pubmed/22366569

Henik R, Dolson M, Wenholz L. How to obtain a blood pressure measurement. Clin Tech Small Anim Pract 2005; 20:144-50. https://www.researchgate.net/publication/7584447 How to Obtain a Blood Pressure Measurement

Mark D Kittleson, William A. Brown. Regurgitant Fraction Measured by Using the Proximal Isovelocity Surface Area Method in Dogs with Chronic Myxomatous Mitral Valve Disease. J Vet Intern Med 2003; 17: 84-88. http://www.ncbi.nlm.nih.gov/pub$\underline{\mathrm{med} / 12564731}$

Nyland TG, Mattoon JS. Diagnóstico Ecográfico en Pequeños Animales. 2a ed. Barcelona, Spain: Multimedica Ed Vet; 2004.

Petit AM, Gouni V, Tissier R, Trehiou-Sechi E, Misbach C, Pouchelon JL, Lefebvre HP, Chetboul V. Systolic arterial blood pressure in small-breed dogs with degenerative mitral valve disease: A prospective study of 103 cases (2007-2012). Vet J 2013; 197: 830-5. http://www.ncbi.nlm.nih.gov/pubmed/23838208

Rondeau DA, Mackalonis ME, and Hess RS. Effect of body position on indirect measurement of systolic arterial blood pressure in dogs. J Am Vet Med Assoc 2013; 242:1523-1527. http://www.ncbi.nlm.nih.gov/pubmed/23683016 
Serres F, Chetboul V, Tissier R, Poujol L, Gouni V, Sampedrano C and Poucelon JL. Comparison of 3 ultrasound methods for quantifying left ventricular systolic function: correlation with disease severity and prognostic value in dogs with mitral valve disease. J Vet Intern Med 2008; 22:566-577. http://www.ncbi.nlm.nih.gov/ pubmed/18466240

Schober KE, Hart TM, Stern JA, Li X, Samii VF, Zekas LJ, Scansen BA, Bonagura JD. Detection of congestive heart failure in dogs by Doppler echocardiography. J Vet Intern Med 2010; 24:1358-68. http://www.ncbi.nlm.nih.gov/pubmed/20840304

Spiegelstein D, Sternik L, Orlov B, Shinfeld A, Feinberg MS, Malachy A, Raanani EJ. Mitral valve repair: isolated posterior compared to anterior or bileaflet pathology. Card Surg 2013; 28:89-96. http://www.ncbi.nlm.nih.gov/pubmed/23294452

Stepien RL, Rapoport GS. Clinical comparison of three methods to measure blood pressure in nonsedated dogs. J Am Vet Med Assoc 1999; 215:1623-8. http://www. ncbi.nlm.nih.gov/pubmed/14567424

Suzuki R, Matsumoto H, Teshima T, Mochizuki Y, Koyama H. Left ventricular geometrical differences in dogs with various stages of myxomatous mitral valve disease. J Small Anim Pract 2013; 54:234-9. http://www.ncbi.n/m.nih.gov/pubmed/23560859

Talavera J, Fernández del Palacio M.J, Agut A, Bayón A. Valvulopatía mitral adquirida crónica en el perro: correlación entre estadio clínico funcional (ISACHC) y signos radiográficos torácicos. Revista Oficial de AVEPA 2001; 21: 122-135. https://ddd.uab. cat/pub/clivetpeqani/11307064v21n2/11307064v21n2p122.pdf

Terzo E, Marcello MD, McAllister H. Echocardiographic assessment of 537 dogs with mitral valve prolapse and leaflet involvement. Veterinary Radiology \& Ultrasound 2009; 50:416-422. http://www.ncbi.nlm.nih.gov/pubmed/19697608

Tou PS, Adin DB, Estrada AH. Echocardiographic estimation of systemic systolic blood pressure in dogs with mild mitral regurgitation. J Vet Intern Med 2006; 20:1127-31. http://www.ncbi.nlm.nih.gov/pubmed/17063704

Walasinee M, Jonathan E, MontSerrat R. Hipertension pulmonar: un problema añadido a los pacientes con enfermedad valvular degenerativa avanzada y patologías respiratorias crónicas. P V Argos 2009. http://argos.portalveterinaria.com/

Zacà V, Brewer R, Khanal S, Imai M, Jiang A, Wang M, et al. Left atrial reverse remodeling in dogs with moderate and advanced heart failure treated with a passive mechanical containment device: an echocardiographic study. J Card Fail 2007; 13:312-317. http://www.ncbi.nlm.nih.gov/pmc/articles/PMC1939806 